\title{
Thermal Performance and Durability of Materials on Concrete-Wood Floor Coverings
}

\author{
Eugenius Pradipto1, Abdul Robbi \\ Maghzaya $^{2}$
}

${ }^{1}$ Department of Architecture, Univeristas Gajah Mada

${ }^{2}$ Department of Architecture, Universitas Islam Indonesia

\author{
Article History \\ Received : 25 September 2020 \\ Accepted : 20 October 2020 \\ Published : 23 October 2020
}

\begin{abstract}
Floor coverings have an important role in buildings. Apart from being the basis for activities in the building, floor coverings also play a role in maintaining room and surface humidity due to the influence of soil and environmental humidity and maintaining room temperature or floor surfaces to be comfortable to use. This function becomes more vital, especially in buildings in a climate where the temperature difference between day and night is large, resulting in very hot days and very cold nights. The problem raised in this study is to offer a floor covering model that can provide a comfortable temperature on the floor surface which results in a quality performance that can keep the surface temperature close to neutral. In this study, observed and tested the temperature and durability of concrete floor blocks with wood branch waste. The construction of this concrete-wooden floor block uses local materials that are easily available and worked on by the common people. The wood elements have the potential to maintain temperature stability in changing environmental temperatures.
\end{abstract}

Keywords: Concrete floor; Thermal Insulator; Wood floor.

\section{Introduction}

Floor coverings have an important role in buildings. Apart from being a working area in the building, floor coverings also play a role in maintaining the thermal quality of the space and surface due to the influence of soil moisture and the environment (Wang et.al, 2018) and maintaining room temperature or floor surfaces so that they are comfortable to use (Benzaama et.al, 2019). This function becomes more vital, especially in buildings located in hot climates (Staszczuk et.al, 2019; Seo et.al, 2014), for example the East Nusa Tenggara region which has a hot dry climate and has relatively low rainfall (Tanesab et.al, 2017).

In general, this area has a distinctive character where the temperature difference between day

Correspondence:Abdul Robbi Maghzaya

Department of Architecture, Universitas Islam Indonesia E-mail: 155120102@uii.ac.id and night can reach $14^{\circ}-18^{\circ} \mathrm{Celsius,} \mathrm{so} \mathrm{that} \mathrm{the}$ sensation felt during the day is hot while the night is very cold.

Recent developments in the use of floor materials have shown that the use of ceramic floor covering materials is quite popular. However, there is an issue that can be observed that apart from the high price, ceramic floors have a weakness because they have low thermal conductivity (1 W m-1K-1) (García et.al, 2011) which impacts the quality of cold surface temperatures at night. This certainly reduces the comfort of building users. The problem raised in this study is to offer a floor covering model that can provide a comfortable temperature on the floor surface which results in a quality performance approaching a neutral temperature (Zhou et.al, 2019), not too hot and not too cold compared to the air temperature conditions in the environment (Jelle, 2011). In this study, observe and test the temperature and durability of concrete floor blocks with wood branch waste. This block construction uses local materials that are easily available 
and worked on by the common people and are durable materials. Also, the material for wooden branches is a material that can be renewed, so that it becomes a material that can continue to be available.

This study aims to see the thermal performance of wood combined with concrete as a floor covering material. In addition, observations of the role and behavior of concrete wood floors in direct contact with the ground are seen from the resistance of the material to the effects of environmental humidity. The benefit of this research is to obtain a floor covering model with cheap waste materials that are easily available and also durable from the surrounding environment. The quality of this composite material can be an alternative material that can be able to condition the temperature on the floor surface which can be comfortable when in direct contact with the user.

\section{Literature Review}

This research model has not been widely used, but the use of wood material as a flooring material is widely found, especially in areas that have a 4-season climate character. In tropical climates (2-season climate character), wooden floors are used on stilts. This type of floor construction is intended to prevent the wood material from coming into direct contact with the ground (Victoria, J et.al,2017). Apart from being able to be used for air circulation, stage floors can also keep floor humidity low due to the influence of good air ventilation (Pellica,G et.al,2020). However, in this study, a study of the durability of wood as a floor composite material in direct contact with the ground. Wooden floors help to provide comfort and warmth to the body surface because the floor can maintain the surface temperature in a stable condition even in an environment that has quite extreme temperature changes (Liu et.al, 2017). In winter temperatures below $0^{\circ} \mathrm{C}$, wood can still give a warm sensation to the touch. Hardwood fibers are not filled with much water which can freeze so that the wood has insulation properties against heat transfer (Kumar et.al, 2016). The development of wooden floors is quite popular as parquet flooring in areas with a climate character of 4 seasons. In Indonesia, although wood material is quite popular, the development of flooring technology with wood is not too widespread.
The price of wood has recently increased and has become expensive. This is because the production of wood cannot keep up with high demand (Morland et.al, 2016). The growing period of wood is a problem in itself to ensure the availability of material supplies. Another problem that develops with the use of wood materials is its influence on climate and environmental ecology by cutting down many trees for building needs (Seppälä et.al, 2019). Many wastes from wood utilization can be used for products that are more efficient than just being used as firewood. This waste wood material can be used as a heat insulation material in buildings (Cetiner et.al, 2018). One of the most common wood wastes is hardwood branches, including shrubs with a diameter of 3-10 cm.

Wood is a material that is easily damaged by insect attacks because the cellulose content in it is termite food. Wood has the character to expand and shrink depending on the humidity conditions of the environment. In high humidity or wet environments, wood will fill in the wood grain so that the wood can expand (Kočí et.al, 2020). When the environment is dry or the humidity drops, the wood will shrink, releasing the moisture content in its cavities and also in the wood fibers. At wood humidity above $20 \%$ with an ambient temperature of $20^{\circ}-27^{\circ} \mathrm{C}$ without heating the sun, blue mushrooms will soon grow within 2-3 days and can soften the wood fibers.

\section{Concrete floors as well as ceramic floors (Astiaso} Garcia, 2016) are building materials that have almost the same properties and behavior. Both can withstand biological destroyers and are designed to withstand water (Medina et.al, 2013; Du et.al, 2016). Concrete material can not provide comfort, especially in areas that have high climate change such as areas with high-temperature fluctuations during the day between $32^{\circ}-38^{\circ} \mathrm{C}$ and $20^{\circ}-25^{\circ} \mathrm{C}$ at night (AlRashed et.al, 2020). Concrete is an artificial material that has good mechanical properties, which can withstand high compressive strength but is vulnerable to tensile forces. Baton also has physical properties that are porous so that it can absorb water from wetter places through direct contact (Fu et.al, 2020). Also, concrete has the property to absorb and store heat and release it later for a long time. Properties like this are less beneficial because during the day the heat in the room can be held longer or vice 
versa at night the cold will be longer.

The duration of heat exposure to building materials affects the thermal comfort response. In hot areas, the floor can function as a radiant cooling system (Zhou et.al, 2019). But in cold areas, the floor must play a role in keeping the room temperature warm. The concretewood composite floor test model was studied as a floor heating system to get a sensation of thermal comfort in a cold environment.

\section{Method}

This research was conducted by observing the wooden-concrete floor block prototype. The prototype is used to see the effect of space or environmental thermal conditions on the physical outer surface of the material. Wood twigs as a composite material were chosen because they are many and easy to find in the surrounding environment. This prototype uses class 3 wood from Acacia wood (Acacia manguium) and guava tree wood (Psidium guajava). The process of making this prototype begins by cutting wooden branches according to the thickness of the floor blocks and laying them in a standing position before casting them with cement sand to get a $40 \times 40 \mathrm{~cm}$ modular block.

The scope of this study is limited to observations of the model for a duration of 5 months. The observation location was conducted in Yogyakarta which has tropical climatic conditions. The wood material used is limited to grade 3 quality wood from guava (Psidium guajava) and acacia (Acacia manguium) wood types.

The testing phase for this prototype begins with arranging the wooden-concrete floor covering block above the ground without bearing, such as sand. Direct contact with the soil is needed to test the resistance of wooden branches from subterranean termites.

The block floor covering of logs and concrete is measured in two test formulations; (1) The resistance of wood to subterranean termites; by looking at the comparison of the results of the experiment in several timeframes and assessing the quality of the upper and lower surfaces of the wooden-concrete floor blocks.

(2) Changes in surface temperature and humidity; tested using 3 measuring instruments in the form; infrared thermometer shafix WT380, Wood moisture tester GM605, and Environment Meter EM-9000.

Figure 1. Infrared thermometer shafix WT380, Wood moisture tester GM605, dan Environment Meter EM-9000

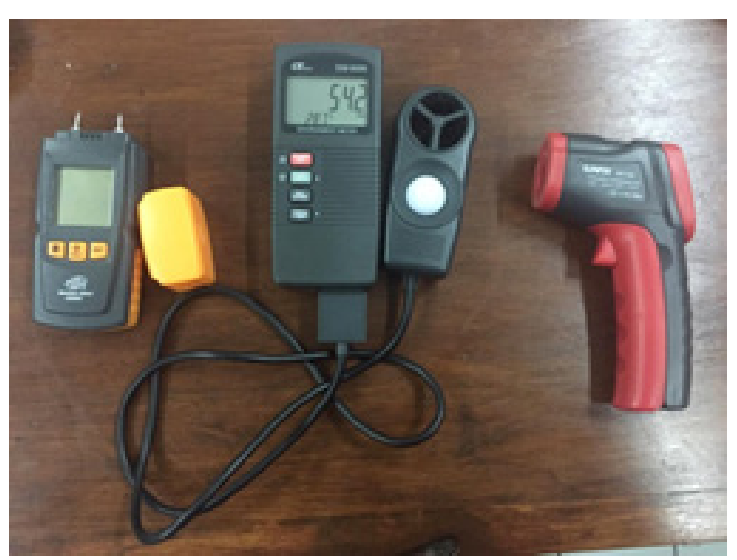

\section{Discussion}

After 5 months of observation, the floor block prototype showed some changes in the resistance of wood to termites. The following is an overview of the results of observations on wooden concrete floor blocks in their reaction to the surrounding environment.

Observations show that after 5 months of installation (Figure 2), there are some damages that can be seen in the concrete wooden floor block. One of them is damage to the wood that has been eaten by termites. Termite damage begins at the bottom of the block in direct contact with the ground (Figure 3).

Figure 2. Installation of wooden concrete floor blocks after 5 months

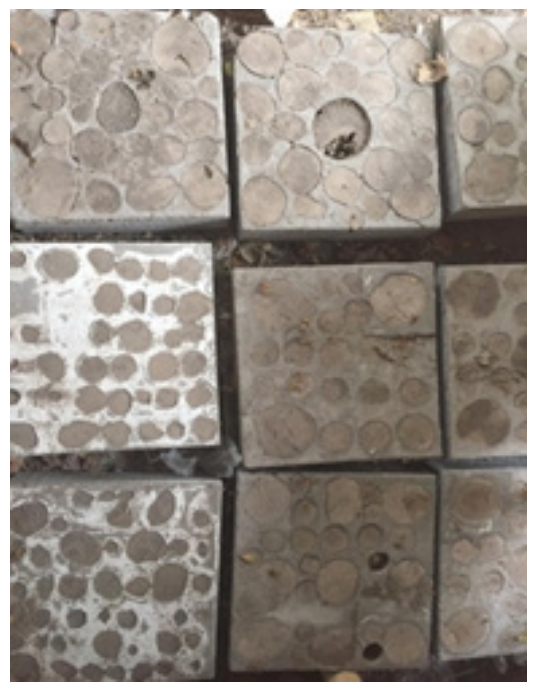


Figure 3. Condition of the bottom side of the floor block after 5 months
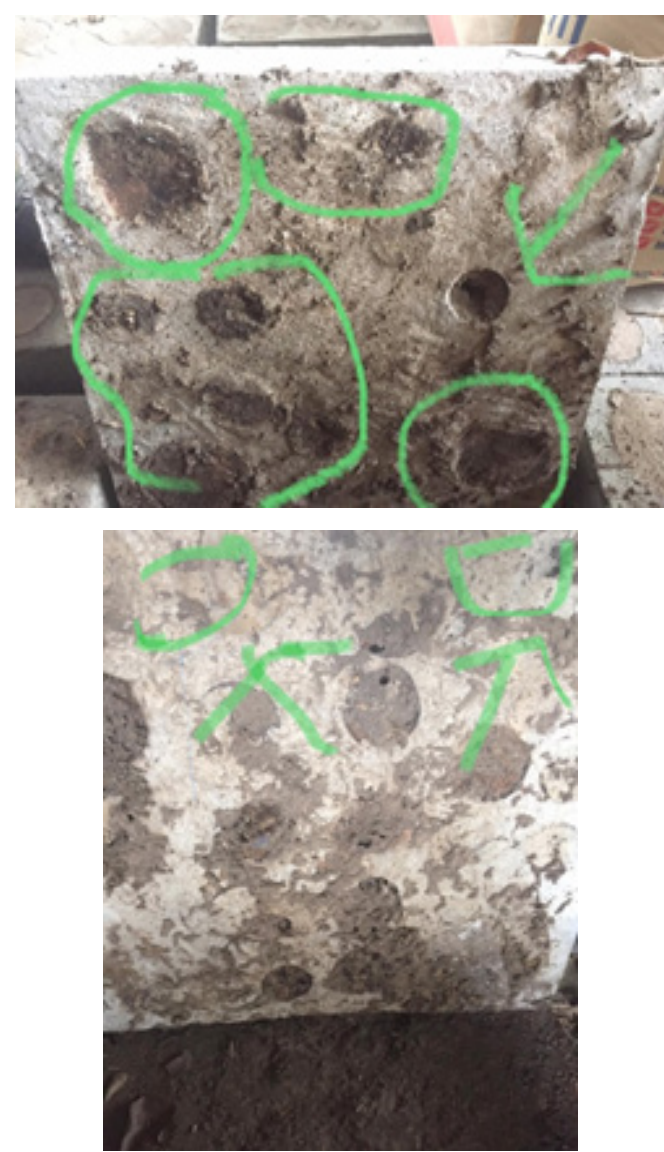

However, although the amount is small, damage to the upper surface of the blocks due to termites also occurs (Figure 4).

The next observable damage is damage to the wood-concrete block construction due to impact. This condition may rarely occur but shows the need to pay attention to how and techniques to tie the logs to one another so that the wood is not separated from the floor block. This type of damage begins with a shrinkage process that occurs in a wooden branch and is released from the concrete as the binding. The wet condition of the wood when it increases the shrinkage effect on the wood so that it shrinks. This condition makes the blocks less cohesive and fragile (Figure 5).
Figure 4. Condition of the top side of the floor block after 5 months
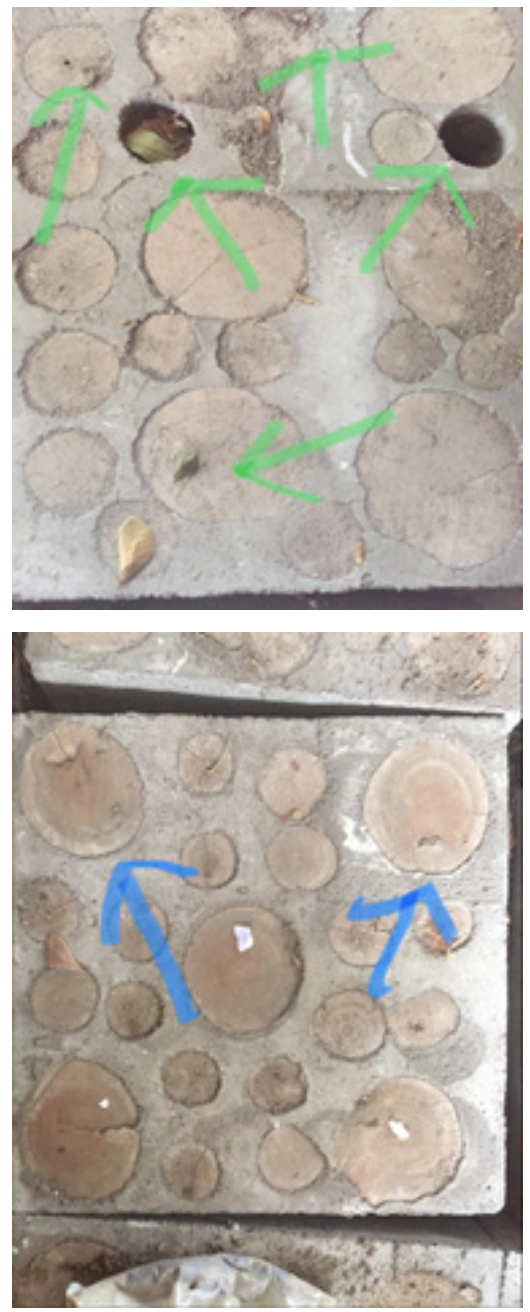
Figure 5. Condition of the top side of the floor block after 5 months
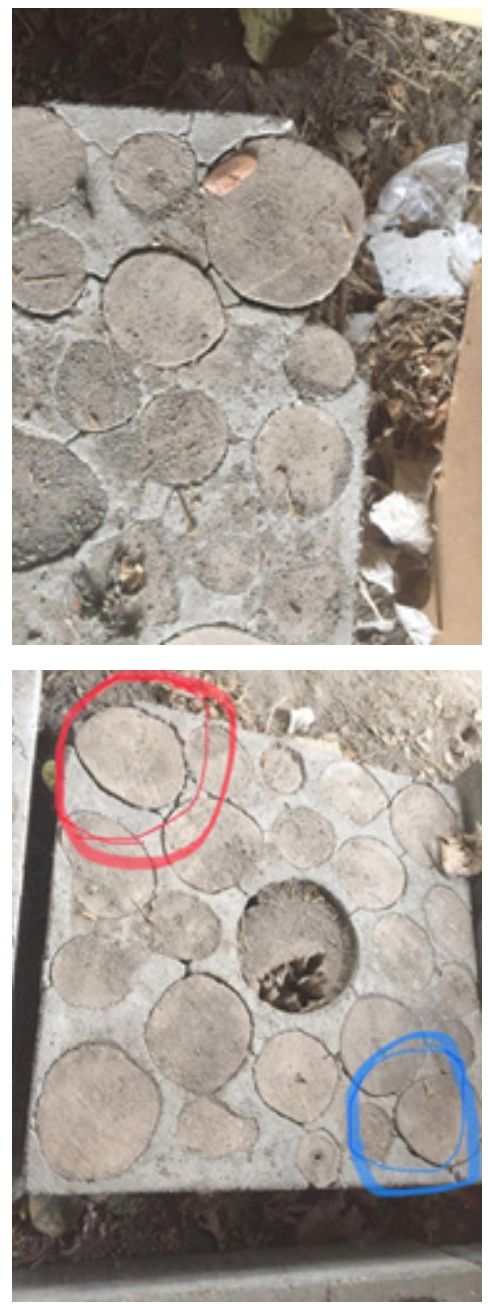

The next observation is to measure the temperature and humidity of the wood-concrete block. The following is a description of the data on the results of temperature and humidity measurements on concrete wood floor blocks.

Table 1. Condition of the top side of the floor block after 5 months

\begin{tabular}{llll}
\hline Surface & & Day & Night \\
\hline \multirow{2}{*}{ Concrete } & Temp. & $27.2^{\circ} \mathrm{C}$ & $25.6^{\circ} \mathrm{C}$ \\
& Humd. & $1.50 \%$ & $3 \%$ \\
\multirow{2}{*}{ Wood } & Temp. & $27.9^{\circ} \mathrm{C}$ & $26.0^{\circ} \mathrm{C}$ \\
& Humd. & $18.00 \%$ & $18.80 \%$ \\
\multirow{2}{*}{ Air } & Temp. & $29.8^{\circ} \mathrm{C}$ & $25.8^{\circ} \mathrm{C}$ \\
& Humd. & $70 \%$ & $79 \%$ \\
\hline
\end{tabular}

The table above shows the different patterns of surface temperature changes between concrete and wood surfaces on changes in temperature measured during the day and night. During the day $\left(29.8^{\circ} \mathrm{C}\right)$, wood and concrete surfaces show a lower temperature than their surroundings. The surface temperature of the concrete shows a temperature of $27.2^{\circ} \mathrm{C}$, a difference of $0.7^{\circ} \mathrm{C}$ compared to the surface temperature of wood, which is $27.9^{\circ} \mathrm{C}$. This proves that concrete material has a greater capacity to absorb heat than wood. But in general, the surface condition of this concrete-wood floor block will feel cold by the user.

The environmental humidity which is high enough also affects the moisture level of concrete and wood materials. The character of the wood that can absorb water is greater, causing the moisture level of the concretewood block material to be greater than that of concrete up to $18 \%$. With greater humidity and the organic properties of the wood material, this is the reason why the wooden parts of the concrete-wood floor block prototype are more easily damaged.

At night, when the average ambient temperature drops to $25.8^{\circ} \mathrm{C}$, the surface temperature of the concrete also drops to $25.6^{\circ} \mathrm{C}$, which is $0.2^{\circ} \mathrm{C}$ lower than the ambient temperature. However, for wood materials, the surface temperature was recorded, although it also fell but was warmer than the ambient temperature, which was $26.0^{\circ} \mathrm{C}$. With a higher temperature than the environment, the sensation felt by the user is warm. This condition will help increase comfort both during the day or night.

\section{Conclusion}

From the observation and testing of the concrete-wood floor block prototype, it can be concluded that the wood in direct contact with the ground is the part that is most susceptible to damage due to termites. Meanwhile, wood that does not come in direct contact with the ground or covered by a layer of concrete does not indicate a termite attack. Low-quality wood begins to show deterioration earlier than hardwood. Choosing the age of the wood material that is too young causes the wood part to experience shrinkage so that it becomes loose and reduces the strength of this wooden concrete floor block.

Changes in temperature and humidity on the surface of the concrete-wood floor block 
indicate that the wood elements have the potential to maintain temperature stability in changing environmental temperatures.

\section{Suggestion}

From the results of trials and observations of the performance of this concrete-wood floor block, it is necessary to further study the method for using wood combined with concrete as a composite material. In addition, it is necessary to develop a concrete-wood composite material that can minimize the influence of moisture on the physical changes of the material. The use of wood with class 1 and 2 quality is recommended to maintain the durability of the wood material. The composition of the wood material must be thinner than the the floor block so that the bottom of the wood will be covered with a layer of concrete to avoid termites and ground humidity. This suggestion aims to improve the quality of performance of concrete-wood floor block technology as an alternative technology in solving issues related to floor construction.

\section{References}

Al-Rashed, R., \& Jabari, M. (2020). Dualcrystallization waterproofing technology for topical treatment of concrete. Case Studies in Construction Materials, Staszczuk, (2019), e00408. https://doi.org/10.1016/j. cscm.2020.e00408

Astiaso, D. G. (2016). Can radiant floor heating systems be used in removable glazed enclosed patios meeting thermal comfort standards?. Building and Environment, Staszczuk, 378-388. https://doi. org/10.1016/j.buildenv.2016.07.013

Berger, F., Gauvin, F., \& Brouwers, H. J. H. (2020). The recycling potential of wood waste into wood-wool/cement composite. Construction and Building Materials, Staszczuk, 119786. https://doi. org/10.1016/j.conbuildmat.2020.119786

Cen, C., Jia, Y., Liu, K., \& Geng, R. (2018). Experimental comparison of thermal comfort during cooling with a fan coil system and radiant floor system at varying space heights. Building and Environment, Staszczuk, (February), 71-79. https://doi. org/10.1016/j.buildenv.2018.05.057

Du, H., Gao, H. J., \& Pang, S. D. (2016). Improvement in concrete resistance against water and chloride ingress by adding graphene nanoplatelet. Cement and Concrete Research, Staszczuk, 114-123. https://doi.org/10.1016/j. cemconres.2016.02.005

Fu, C., Zhu, Y., \& Wang, Y. (2020). Stiffness assessment of cracked post-tensioned concrete beams with unbonded tendons based on the cracking pattern. Engineering Structures, Staszczuk, (April), 110599. https://doi.org/10.1016/j. engstruct.2020.110599

García, E., De Pablos, A., Bengoechea, M. A., Guaita, L., Osendi, M. I., \& Miranzo, P. (2011). Thermal conductivity studies on ceramic floor tiles. Ceramics International, Staszczuk, (1), 369-375. https://doi. org/10.1016/j.ceramint.2010.09.023

Jelle, B. P. (2011). Traditional, state-of-theart and future thermal building insulation materials and solutions - Properties, requirements and possibilities. Energy and Buildings, Staszczuk, (10), 2549-2563. https://doi.org/10.1016/j. enbuild.2011.05.015

Kočí, V., Jerman, M., Pavlík, Z., Maděra, J., Žák, J., \& Černý, R. (2020). Interior thermal insulation systems based on wood fiberboards: experimental analysis and computational assessment of hygrothermal and energy performance in the Central European climate. Energy and Buildings, Staszczuk. https://doi.org/10.1016/j. enbuild.2020.110093

Kuczyński, T., \& Staszczuk, A. (2020). Experimental study of the influence of thermal mass on thermal comfort and cooling energy demand in residential buildings. Energy, Staszczuk,. https://doi. org/10.1016/j.energy.2020.116984

Kumar, A., Staněk, K., Ryparová, P., Hajek, P., \& Tywoniak, J. (2016). Hydrophobic treatment of wood fibrous thermal insulator by octadecyltrichlorosilane and its influence on hygric properties and resistance against moulds. Composites Part B: Engineering, Staszczuk, 285-293. https://doi. org/10.1016/j.compositesb.2016.09.034

Liu, C., Luo, R., Zhou, S., \& Du, G. (2017). The Construction of Heat Storage Performance Testing Method of Wood Materials used for Floor Heating. Procedia Engineering, Staszczuk, 3804-3810. https://doi. org/10.1016/j.proeng.2017.10.116

Medina, C., Sánchez De Rojas, M. I., \& Frías, M. (2013). Properties of recycled 
ceramic aggregate concretes: Water resistance. Cement and Concrete Composites, Staszczuk, 21-29. https://doi. org/10.1016/j.cemconcomp.2013.04.005

Morland, C., Schier, F., Janzen, N., \& Weimar, H. (2018). Supply and demand functions for global wood markets: Specification and plausibility testing of econometric models within the global forest sector. Forest Policy and Economics, Staszczuk, (March), 92-105. https://doi.org/10.1016/j. forpol.2018.04.003

Pelliccia, G., Baldinelli, G., Bianconi, F., Filippucci, M., Fioravanti, M., Goli, G., Rotili, A., \& Togni, M. (2020). Characterisation of wood hygromorphic panels for relative humidity passive control. Journal of Building Engineering, 32(July 2019), 101829. https://doi.org/10.1016/j.jobe.2020.101829

Seppälä, J., Heinonen, T., Pukkala, T., Kilpeläinen, A., Mattila, T., Myllyviita, T., Asikainen, A., \& Peltola, H. (2019). Effect of increased wood harvesting and utilization on required greenhouse gas displacement factors of wood-based products and fuels. Journal of Environmental Management, Staszczuk, (June), 580-587. https://doi. org/10.1016/j.jenvman.2019.06.031

Seo, J. M., Song, D., \& Lee, K. H. (2014). Possibility of coupling outdoor air cooling and radiant floor cooling under hot and humid climate conditions. Energy and Buildings, Staszczuk, 219-226. https://doi. org/10.1016/j.enbuild.2014.06.023

Staszczuk, A., \& Kuczyński, T. (2019). The impact of floor thermal capacity on air temperature and energy consumption in buildings in temperate climate. Energy, Staszczuk, 908-915. https://doi. org/10.1016/j.energy.2019.05.202

Tanesab, J., Parlevliet, D., Whale, J., \& Urmee, T. (2017). Seasonal effect of dust on the degradation of PV modules performance deployed in different climate areas. Renewable Energy, Staszczuk, 105-115. https://doi.org/10.1016/j. renene.2017.03.091

Victoria, J., Mahayuddin, S. A., Zaharuddin, W. A. Z. W., Harun, S. N., \& Ismail, B. (2017). Bioclimatic Design Approach in Dayak Traditional Longhouse. Procedia Engineering, 180, 562-570. https://doi. org/10.1016/j.proeng.2017.04.215

Zhou, X., Liu, Y., Luo, M., Zhang, L., Zhang, Q., \& Zhang, X. (2019). Thermal comfort under radiant asymmetries of floor cooling system in $2 \mathrm{~h}$ and $8 \mathrm{~h}$ exposure durations. Energy and Buildings, Staszczuk, 98-110. https:// doi.org/10.1016/j.enbuild.2019.02.009 